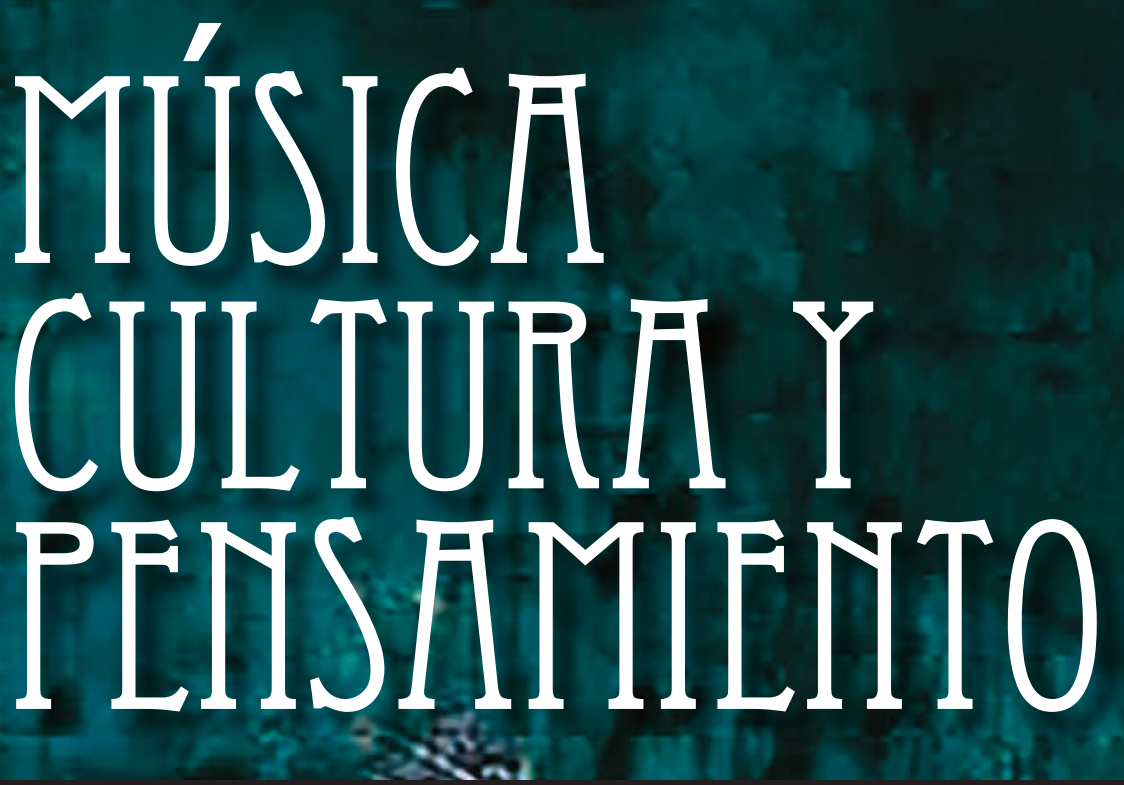

Revista de investigación de la Facultad de Educación y Artes del Conservatorio del Tolima
VOL. VII N.` 7 - Enero 2018
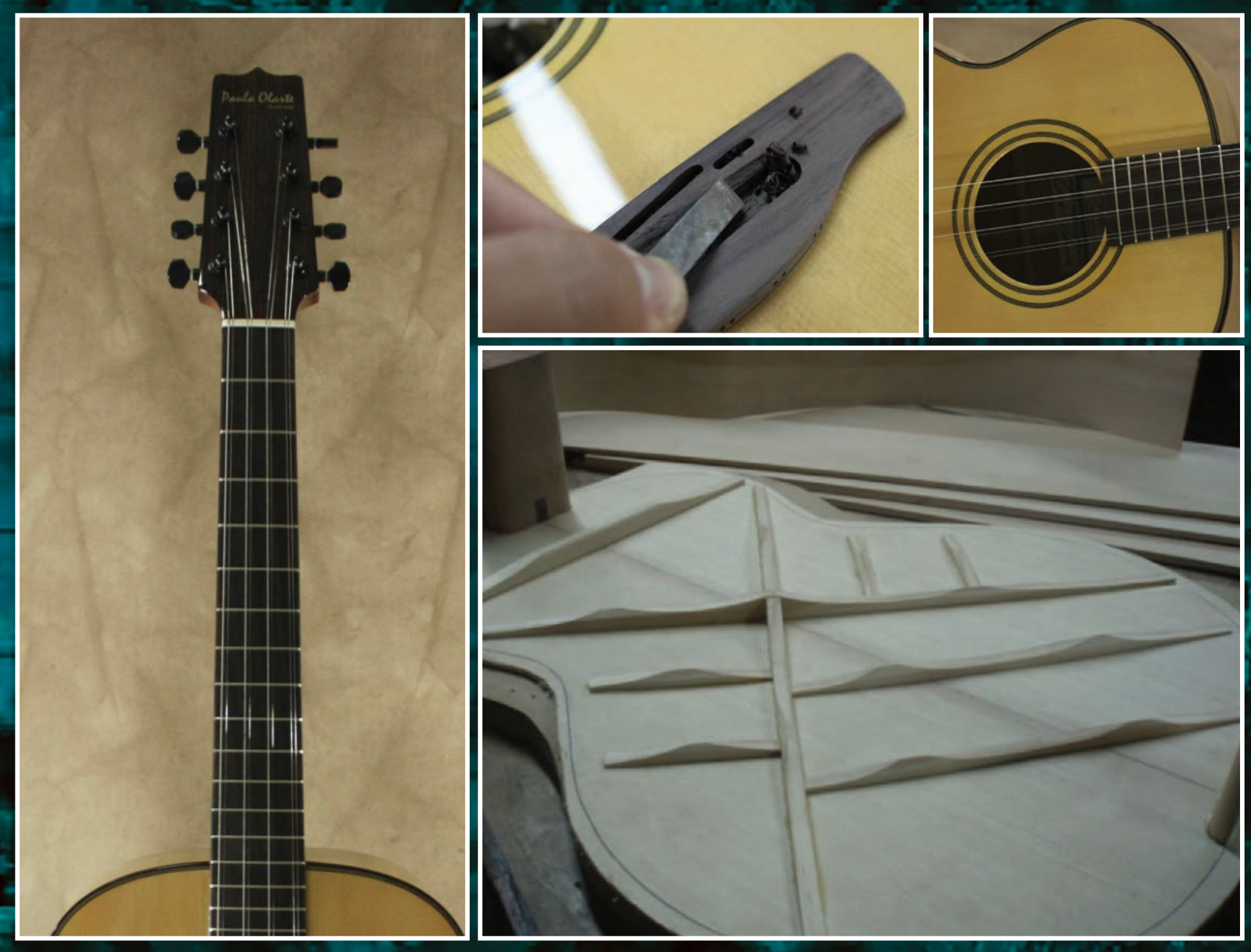


\section{Ruana y carranga: dos símbolos campesinos de origen múltiple}

Por: Leonardo Zambrano Rodríguez ${ }^{1}$

Artículo de investigación

Recibido: 15 de diciembre del 2016

Aprobado: 15 de junio del 2017

Para citar este artículo/To reference this article Zambrano, L. (2017). Ruana y carranga: dos símbolos campesinos de origen múltiple. Música, Cultura y Pensamiento, 7 (7), 6-17.

1 Este artículo es producto de la investigación llamada "Ruana y Carranga: una visión cinematográfica de la música carranguera como fenómeno social y de resistencia cultural del campesinado cundiboyacense", la cual se llevó cabo en la Universidad Central entre los años 2014 y 2015. Para una mayor información sobre el proyecto se puede consultar una reseña publicada en el número 42 de la revista Nómadas de la Universidad Central, disponible en este enlace: http://nomadas.ucentral.edu.co/index.php/2198-imaginacion-cientifica-o-imposturas-de-la-tecnociencia-nomadas-42/ resenas/835-ruana-y-carranga-una-vision-cinematografica-de-la-musica-carranguera-como-fenomeno-social-y-de-resistencia-cultural-del-campesinado-cundiboyacense.

Leonardo Zambrano Rodríguez es Magíster en Música de la Universidad Eafit, ha trabajado como docente de materias teóricas, piano y como investigador en universidades e instituciones colombianas como la Escuela de la Orquesta Sinfónica Juvenil, Academia Fernando Sor y en la Universidad Central. Izambranor@ucentral.edu.co

\section{Ruana and carranga: Two rural symbols of multiple origin}

\begin{abstract}
Resumen
Este escrito pretende dar cuenta de la importancia de la música campesina de la región centro-oriente de Colombia. Al ser un elemento comunicativo e integrador entre los campesinos, la música campesina, cuyo origen, aunque difícil de determinar, ofrece la oportunidad de su estudio al preguntarse sobre el medio en el cual esta música se produce y circula construyendo la identidad de un grupo cultural y ampliando su territorio simbólico.
\end{abstract}

Palabras clave: música campesina, territorio, identidad, sociedades musicales, grupos culturales.

Title: Ruana and carranga: Two rural symbols of multiple origin, by Leonardo Zambrano Rodríguez.

\begin{abstract}
This article aims to offer an account of the importance of rural music from the center-east region of Colombia as a communicative and integrating element among farmers, its origin, although difficult to determine, can be studied by asking about the environment in which this music is produced and circulated; therefore, constructing the identity of a cultural group and expanding its symbolic territory.
\end{abstract}

Keywords: folk music, territory, identity, musical societies, cultural groups. 


\section{Introducción}

$E^{n}$ n el 2005 la National Geographic lanzó su proyecto de investigación Ilamado The Genographic

Project en el que mediante el análisis del ADN de diversas poblaciones intentaba rastrear el origen del ser humano; de hecho en su sitio $w^{2} b^{2}$ se vende un kit mediante el cual las personas interesadas en participar en este estudio pueden enviar su prueba de ADN. Novedosas técnicas de computación pueden sistematizar la información de lo que los científicos que dirigen este proyecto Ilaman marcadores, así se puede identificar a los ancestros de los individuos participantes. Dos de los resultados de este proyecto fueron la reconstrucción de la ruta migratoria de los seres humanos y la búsqueda de las explicaciones de la diversidad humana. Una de las posibles conclusiones a la que ha llegado este rastreo de las rutas migratorias del ser humano por el mundo, es que salió de África y terminó en Brasil. En este último país existen humanos que poseen una combinación de rasgos de todas las genealogías. Por supuesto, esta conclusión no es definitiva y aún quedan interrogantes complejos por resolver, pero lo interesante de este proyecto y la razón por la cual se trae a colación es porque es un buen ejemplo de la preocupación que siempre tenemos por indagar sobre nuestro origen y el origen de las cosas. Preguntarse por el origen de algo puede agotar el tema rápidamente si el motivo de este interrogante es indagar sobre una fecha o un periodo de tiempo determinado, pero la pregunta cobra fuerza cuando en la indagación van surgiendo los diferentes aspectos que configuran ese origen, entonces este se complejiza; ese origen se convierte en un sistema conformado por una serie de acontecimientos.

\section{La ruana y la música campesina: dos símbolos de la región centro-oriente de Colombia}

Al igual que se han mezclado las diferentes genealogías de seres humanos, la música campesina es producto del encuentro de diferentes expresiones. Rastrear su origen sería una tarea que implicaría analizar el ADN musical, los motivos o células ritmo-melódicas e indagar sobre su transformación paulatina, una tarea que resultaría onerosa. Pero lo interesante de preguntarse por el origen de esta música radica en que formular este interrogante implica también enfocarse en el medio en donde nace, la tierra fértil donde germina, porque, al igual que la zanahoria, la cebolla o la papa, como lo comentara Ana Cecilia Fajardo, profesora de la Universidad de Cundinamarca durante una conversación informal, dicha música parece brotar de la tierra. "En cada loma hay una vereda y entre una loma y otra hay un hueco, pero en cada una de ellas surge la música campesina como si fuera un espíritu viajero". Esta música es un elemento vital que está presente en casi todas las actividades de la gente del campo, no solo a manera de un elemento accesorio que hace las veces de compañía, sino que se convierte en un

2 La página se puede consultar en https://genographic.nationalgeographic.com/for-scientists/. componente integrador que sirve como medio de comunicación, además de generar sentido de identidad y de cohesión grupal. Es un símbolo que, lo mismo que la ruana, permite identificar al campesino de la región centro-oriente de Colombia.

En el aspecto de la construcción de una identidad cultural mediante la música, resulta interesante el planteamiento de Cook (2001), quien Ilama la atención sobre la manera como se utiliza la música como una forma de comprender culturas y de negociar identidades. En esta perspectiva afirma:

Y si utilizamos la música como un modo de comprender otras culturas, entonces podemos verla igualmente como un medio de negociar la identidad cultural... un ejemplo más completo es la música australiana de la postguerra: compositores como Peter Sculthorpe se han valido de músicas nativas de Australia y de Asia Oriental de tal modo que han contribuido a la reubicación cultural y política más amplia de Australia como una parte integral de la religión emergente de los países del Pacífico, en vez de como cultura europea en una parte del mundo equivocada. Podría contarse una historia similar, aunque más conflictiva, de la combinación y separación de los estilos chinos, otros asiáticos orientales e 
internacionales de la música popular y "culta" en el Hong Kong de la postguerra; la música ha dado voz a la búsqueda de identidad cultural de la antigua colonia, ya sea por derecho propio o, desde 1997, como parte de una identidad más amplia. (No ha representado esa búsqueda; ha sido parte de ella). Si la música no permitiera algún tipo de intercomunicación cultural, entonces no podría utilizarse de este modo. Y esto significa que la música se convierte en un modo no solo de obtener una cierta comprensión del otro cultural, sino también de mover nuestra propia identidad en el curso del proceso. La música, en suma, representa un modo de salir del pensamiento cultural (p. 161).

Así como cuando el campesino lleva su ruana a la ciudad en un intento de expandir su añorado campo, de la misma manera carga con su música para dar a conocer de dónde viene, cuáles son sus orígenes y trasladar su territorio de una manera simbólica hacia otras tierras. Una evidencia de lo anterior, es el hecho de que un buen número de grupos musicales veredales de la región andina se autodenominan con nombres que hacen referencia a su apellido o a su lugar de procedencia: Los Hermanos Amado, Los Reyes de Santander, Los Hermanos Mesa, Pulidos Son, Los Primos de Vélez, entre otros. La ruana, en estos grupos, es un elemento que es indispensable en cada presentación y también constituye una proyección de su identidad. Esta prenda está asociada a las maneras de vivir en el campo y transmite una imagen pública que es identificable por la sociedad. Tanto la música que nos ocupa en este escrito, así como la ruana provienen del encuentro entre diferentes culturas. La teoría sobre el origen del nombre de esta prenda de vestir señala que es una transformación de la palabra ruen, una población en Francia de donde se importaban las telas que se usaban en su fabricación (González, 2012). Con respecto a la ruana del altiplano cundiboyacense, se maneja la teoría de que proviene de una mezcla entre el "poncho" que introdujeron los yanaconas durante el coloniaje español en las tierras de la provincia de Tunja y el capote español (Amaya, 2013, p. 6).

\section{LO QUE MÁS QUIERO ${ }^{3}$}

Cuando salí de mi tierra dejé lo que yo más quiero mi novia en un mar de llanto

\footnotetext{
3 La canción se puede escuchar en el siquiente enlace https:// www.youtube.com/watch?v=Rh5VMcqFiSg.
}

\author{
$y$ entre sollozos mis viejos \\ pero me traje mi ruana lo mismo que mi sombrero \\ porque los dos me acompañan desde que estaba pequeño \\ dejé solita mi novia y dejé solitos mis viejos \\ pero los traigo en el alma \\ $y$ por ellos vivo y me muero. \\ $Y$ cómo quiero mi novia \\ y cómo quiero mis viejos \\ y cómo quiero mi ruana \\ lo mismo que mi sombrero \\ me gusta ser de mi tierra \\ me gusta ser parrandero \\ me gusta hacer musiquita \\ para alegrar a mi pueblo \\ me gusta ser el guasquito \\ que lleva ruana y sombrero \\ por eso vuelvo y repito \\ que quiero lo que más quiero.
}

Autor: Libardo González Interpreta: El Son de Allá

La ruana de la región andina en la actualidad tiene una gran carga simbólica, tanto en las redes sociales como de manera física; sirvió como un ícono que indicaba el apoyo por parte de la opinión pública a las luchas campesinas durante el Paro Nacional Agrario realizado en Colombia en el 2013, y para los campesinos fue la bandera que enarbolaron como emblema de su movimiento. La manera como los grupos sociales se comunican mediante signos y símbolos ha sido tratada desde la semiótica por Squicciarino (1986), quien, en este sentido, propone que la indumentaria es un elemento que produce significado y acerca el concepto de signo al de símbolo.

[...] la semiótica no puede limitarse a los fenómenos de comunicación intencional: debe interesarse por todo aquello que haga referencia a un significado, prescindiendo del hecho de que tal significación tenga o no la intención explícita de comunicar. "La semiótica" - precisa Eco"tiene que ver con cualquier cosa que pueda ser concebida como signo. Signo es todo aquello que puede ser entendido como un sustituto significativo de alguna cosa". En este sentido, el inconsciente, definido por Freud como "un signo distintivo a falta de un conocimiento mejor", también tendría que desempeñar la función de signo, convirtiéndose en objeto de análisis en su momento de codificación y de decodificación como si se tratara del mensaje enviado en un código de un emisor a un receptor. En el plano 
de los estudios semióticos, los distintos elementos de la indumentaria, precisamente porque están cargados de significado y más caracterizados por su valor simbólico que por el valor funcional, pueden considerarse como parte de un proceso de significación, es decir, asumen la función de signo, ya sea como vehículos del inconsciente o como objetos de consumo (p. 21).

Por su parte, la música también sirve como un medio para transmitir significado, bien sea mediante sus características estructurales inmanentes que la hacen reconocible o identificable como perteneciente a una región determinada, así como también a través de las letras de las canciones. En esta perspectiva, la indumentaria en combinación con la música, sus textos (letras) y los instrumentos típicos que la caracterizan, conforman un todo significante mediante el cual los campesinos comunican un discurso social que ayuda a configurar su identidad.

Los discursos sociales constituyen identidades a través de la interpelación de los sujetos. Los discursos establecen redes de significados compartidos que propician un sentido de pertenencia, ciertas prácticas y un horizonte de futuro común. Es decir, crean identidades públicas que, además, inciden en el desarrollo de prácticas y de una autopercepción en el ámbito de la identidad de cada uno de los sujetos interpelados (Ramírez, 2006, p. 248).

Esta construcción colectiva de pertenencia a un grupo que esta música genera entre los campesinos se explica en nuestra condición de seres sociales, en que la condición de pertenencia a un grupo es una de nuestras necesidades básicas. Alrededor de los diferentes géneros musicales se construyen maneras de ser o de actuar propias de determinado grupo cultural y se busca reconocimiento entre ellos y, por otro lado, se logra satisfacción psíquica y emocional, y una diferenciación subjetiva con otros grupos. Tal como lo afirma Vila (2002), "la música permite la ubicación cultural del individuo en lo social, así la música puede representar, simbolizar y ofrecer la experiencia inmediata de una identidad colectiva" (p. 21).

La ruana y la música que acompañaron el ya mencionado Paro Agrario también están presentes en gran parte de las actividades campesinas. Las principales parcelas de cultivo en donde esta música ha fortalecido sus raíces han sido la familia, las celebraciones religiosas y la apropiación y aprendizaje musical que se realiza mediante la oralidad e imitación. Con respecto a la familia, existen casos en los que se han conformado grandes clanes de músicos, como el de la familia Amado, en cuyo seno han surgido una veintena de agrupaciones. Otro caso es el de la familia de Tomás Vanegas (2015), quien afirma que las reuniones familiares se prolongan hasta por tres días gracias a que muchos integrantes de su familia son músicos y pueden turnarse para amenizar la fiesta. Nicole Ocampo (2014) recoge varios testimonios de músicos campesinos de la región a este respecto y con base en ellos afirma:

la familia ha llegado a ser determinante para cada uno de los músicos que hoy en día componen y hacen música campesina carranguera. En la mayoría de los casos existe un "taita", un abuelo, un tío, un primo que ha tocado tiple o requinto y que ha cantado en reuniones familiares, fiestas o en los espacios más cotidianos como lo son las noches del campo en el rancho, sirviendo de inspiración para los más pequeños ( p. 75).

En lo que tiene que ver con las celebraciones religiosas, estas son un espacio en el que los músicos son protagonistas indispensables. Para el caso de la región centro-oriente de Colombia, en la cual se enfoca este escrito, entre otras celebraciones religiosas, se puede mencionar el baile de San Pascual y las Romerías, eventos que han contribuido al surgimiento de agrupaciones veredales y aunque en la actualidad ya no se llevan a cabo con la frecuencia de tiempos pasados, sí fueron un pilar importante en la conformación de esta expresión musical.

Otro espacio que ha contribuido al surgimiento del movimiento musical campesino es el del aprendizaje musical que se realiza en las veredas de manera espontánea, porque todos se conocen y porque además de la amistad, también se relacionan por medio del compadrazgo, tal como lo afirma Fals Borda (1961) para el caso de Saucio (departamento de Boyacá), el cual se puede extrapolar a otras poblaciones:

los vínculos sociales y sentimentales entre las personas se ramifican mediante un complicado sistema de relaciones Ilamado 'compadrazgo' que ha tenido por consecuencia la intensificación y el fortalecimiento de la organización familiar extensa de Saucio y la creación de grupos de amistad. Este parentesco espiritual vincula a los ahijados con sus padrinos y madrinas, que para los de los padres de los primeros son compadres y comadres (p. 243). 
Desde la cotidianidad, es el compadrazgo lo que estimula a que los campesinos, al oír las interpretaciones de sus amigos y compadres, se interesen por aprender y soliciten ser enseñados o simplemente lo hagan por imitación. Hoy en día existe una vasta oferta de instituciones formales e informales en donde los campesinos pueden aprender su música, pero varios de los músicos campesinos entrevistados coinciden en afirmar que aprendieron escuchando o compartiendo conocimientos con sus amigos. Un ejemplo de lo anterior es el caso de Marcos Pérez quien aprendió con Juan Eulogio Meza en Sogamoso, o el de Anselmo Mesa, quien se ha encargado de enseñarles a varios habitantes de la vereda El Crucero (ambas poblaciones ubicadas en el departamento de Boyacá). Las relaciones que se entretejen en las poblaciones gracias al interés de algunos de sus habitantes por aprender su música también genera un sentido de pertenencia

en la medida en que configura un universo de sentidos que permite una identificación intersubjetiva. Este sentido de pertenencia propicia estilos de vida cercanos al orden de la proxemia y forma grupos que pueden ser parecidos a la noción de familia usada por Maffesoli, es decir, como familia ampliada (Ramírez, 2006, p. 250).

En la canción Canto a mi vereda $a^{4}$ el compositor Jorge Velosa describe con bella poesía las relaciones que surgen en estos lugares:

Mi vereda parece un pesebre

hay casitas en todo lugar, alla'rriba vive mi abuelita y por all'abajo vive don Pascual.

Hay Rodríguez, Buitragos, Guerreros, Ruices, Castellanos, Torres por doquier y Marías, Auroras, Carmelas $y$ otros cuantos lindos nombres de mujer.

El poder simbólico de la ruana y de la música campesina llamó la atención de Jorge Velosa, quien en 1970 conformó el grupo musical Los Carrangueros de Ráquira, haciendo referencia tanto al conocido oficio de traficar con carne poco apta para el consumo humano, como al pueblo de donde es oriundo este artista colombiano. El grupo obtuvo reconocimiento a escala nacional e internacional y su música se popularizó con el apoyo de los medios de comunicación. Los Carrangueros de Ráquira focalizaron su proyecto en interpretar la música campesina típica de la región del altiplano cundiboyacense y Santan-

4 Álbum En cantos verdes. Velosa y los Carrangueros (1998). der del Sur, localizada en el centro y oriente de Colombia. Gracias a la visibilidad que logró, el público comenzó a asociar esta música con el nombre de este grupo musical y de ahí que desde entonces se la reconozca como "música carranguera". Carranguero es un término irreverente, va en contra de lo formal, genera escozor entre quienes conocen su significado original, pero por otro lado resulta sonoro y llamativo para quienes lo desconocen. Una de las canciones que interpretó el grupo en sus inicios fue titulada $E I$ carranguero ${ }^{5}$, la cual más tarde haría parte del álbum Así es la vida, de 1982. El carranguero es una canción en la que se pueden escuchar, en los instrumentos de cuerda, elementos del joropo llanero y del son huasquero mexicano, mientras la guacharaca ejecuta el patrón rítmico típico del merengue campesino. En su letra se cuentan las peripecias de un traficante que busca comercializar la carne de un toro en condiciones poco saludables para el consumo humano. Al final de la canción queda la moraleja de que este tipo de actividad no es buen negocio. Según Jorge Velosa, esta fue la canción con la que se presentaron en el concurso Guitarra de Plata en Chiquinquirá, y la que, más adelante, le daría el nombre al grupo. Llamarse carranguero también es una forma de enfrentarse a lo establecido, basta mirar la reacción de algunas personas que defienden a la música académica como la única expresión musical de carácter cultural elevado, cuando se menciona la "música carranguera", es una forma de poner el dedo en la llaga, una manera de gritar "aquí estamos", "así somos". Sin embargo, la palabra carranguero ha ido perdiendo su acepción original y, hoy en día, ha adquirido el significado de un intérprete de música campesina de Boyacá. Por supuesto, lo anterior corresponde a un imaginario generalizado, ya que la región de incidencia de la música carranguera no se limita únicamente a ese departamento colombiano.

La aparición de Jorge Velosa en el escenario de la música campesina de la región boyacense es un acontecimiento que bifurca la historia de estas músicas del centro de Colombia. En ese momento comienza a gestarse un movimiento, que según el mismo Velosa, se convertiría en un género musical. Antes de que este movimiento carranguero cobrara fuerza en el ámbito comercial y se instaurara, además, como parte de la cultura colombiana, la música campesi-

\footnotetext{
$5 \mathrm{El}$ carranguero: https://www.youtube.com/watch?v=kUlPqC25is4, Son huasquero: El querreque: https://www.youtube.com/watch?v=RHJhBLW4DvU, joropo: https://www.youtube.com/watch?v=r7legHERdNs.
} 
na de esta región recibía la denominación específica de acuerdo con cada aire. Es así como se les llamaba merengues, rumbas, zambas o redovas, entre otros. Sin embargo, con la adopción de la expresión música carranguera, todos esos aires comenzaron a ser vistos como parte de este nuevo "género". Lo cierto es que hubo un cambio de denominación, pero la música seguía siendo esencialmente la misma. Esta problemática también es planteada en el trabajo de Ocampo (2014) y ella decide solucionarlo usando la expresión músicas carrangueras campesinas. Según algunos de los juglares de la región como los maestros Jacinto Amado fundador del conjunto Los Hermanos Amado de la vereda de San Pedro de Iguaque y Álvaro Suesca director de la agrupación $E$ I Pueblo Canta del municipio de Tuta (Ocampo, 2014), representantes importantes de este quehacer musical, la música carranguera es la que se interpreta con el formato que se estableció después del éxito de la propuesta de Velosa, consistente en guitarra marcante, tiple, requinto y guacharaca, pero aclaran que el merengue campesino y la rumba criolla aún mantienen su propio espacio y no podrían enmarcarse dentro de la música carranguera, ellos afirman que todas estas expresiones en su conjunto hacen parte de la música campesina en general. Este tema resulta problemático y no hay precisión en cuanto a la clasificación. Dentro de este marco, la propuesta que aparece en la "Cartografía de prácticas musicales de Colombia" de la Biblioteca Nacional es la de denominarlas como "músicas andinas centrooriente", en esta categoría están contenidos, según se expresa en este medio, "dos grandes sistemas de músicas: el torbellino y la música carranguera", y se incluye dentro del torbellino a las "cantas de guabina”. El asunto con esta propuesta es que no contempla que junto con la música carranguera, además, conviven la rumba y el merengue campesinos, los cuales difieren de la música carranguera en cuanto a su formato instrumental y son más propios de un sector de músicos pertenecientes a agrupaciones veredales. La música carranguera es un sistema musical que tiene una complejidad diferente a la de los del merengue y la rumba campesinos.

El tema sobre la clasificación de estas músicas se trató durante un encuentro con varios intérpretes realizado en la ciudad de Tunja (Boyacá), como parte del proyecto de investigación que ha motivado el presente

6 http://www.bibliotecanacional.gov.co/content/cartograf\%C3\%AD-de-pr\%C3\%A1cticas-musicales-en-Colombia. artículo. Una de las opiniones expresada de manera generalizada por los intérpretes es que no se debe confundir la música carranguera con la música folclórica (a la cual también se refieren como música tradicional popular). Afirman que se nota una diferencia muy marcada entre la música popular campesina y la música folclórica; que esta última viene de hace mucho tiempo, que no se sabe quién se la inventó. Explican que la música más representativa de la región de Cundinamarca, los Santanderes y Boyacá son los torbellinos, las rumbas criollas, la contradanza, las guabinas y el bambuco. Por el contrario, con respecto a la música carranguera, opinan que es un género que Jorge Velosa se inventó. Cuentan que él comenzó a experimentar con la música folclórica y a "darle más velocidad", porque pensaba que se podía volver, en palabras de ellos, más "revolucionaria". "Revolucionaria”, en este contexto, debe entenderse con el sentido de innovadora, de que tenía el objetivo de sacudir las expresiones musicales tradicionales que se daban en ese momento. La clasificación que los músicos de la región hacen sobre los diferentes géneros de estas músicas aún necesita precisión, se habla de "música campesina tradicional”, de "música folclórica” y de "música popular campesina", y hacen énfasis en que la "música carranguera" es un nuevo género que surge como una propuesta de Jorge Velosa a partir de la experimentación que él hacía con la música tradicional andina.

El merengue y la rumba campesina subsisten entre los grupos veredales, quienes actúan en celebraciones familiares, diferentes festividades y conmemoraciones religiosas, aunque debido a la influencia de la música carranguera, que es comercialmente más fuerte, sus características en cuanto a formato instrumental y elementos musicales se han ido fusionando. La rumba y el merengue campesinos fueron incorporados dentro de la música carranguera, pero los músicos de la región los Ilaman merengue y rumba carrangueros, estos últimos se diferencian de los primeros en cuanto al tempo, resultan ser más ágiles y en las elaboraciones melódicas del requinto que son más floridos, mientras los de la guitarra puntera son más sencillos. Otra diferencia tiene que ver con la guitarra marcante, las líneas melódicas que este instrumento ejecuta en la música carranguera son muy similares a las del bajo (ejecutado por el bombardino) en la música norteña mexicana. Este se caracteriza por el uso de notas de paso que conectan los cambios de armonía y por efectos de glissando cuando hay saltos. La guitarra marcante en el merengue y rumba campesinos apoya la estructura rítmica con los bajos de cada acorde, pero casi 
no hace elaboraciones melódicas. Se puede afirmar que el merengue y la rumba campesinas tienen su campo de acción en espacios más íntimos como la familia, los vecinos, los amigos. La música carranguera, en cambio, se mueve en las celebraciones de mayor asistencia de público como festivales, convites y concursos. La música carranguera no solo incorporó las características del merengue y la rumba campesinos, sino que además se apropió de una gran variedad de músicas tradicionales colombianas y de otras naciones, lo cual ha generado la cantidad de variantes que este sistema musical posee.

Durante el trabajo de campo, los músicos campesinos se referían a diferentes variantes estilísticas del merengue y la rumba carrangueras, pero no había un acuerdo en cuanto a su denominación. En su trabajo sobre las características musicales de estos aires, Gallardo y Carrido (2010) proponen una sistematización de esas variantes de la siguiente manera: 1) merengue carranguero: merengue bambuquiao, merengue joropiao, merengue apasillao, merengue torbellino, merelao (mezcla de merengue y currulao); 2) rumba carranguera: rumba ligera, rumba amarrada, rumba ronda, rumba corrida y rumba rap. Algunas de estas denominaciones dan cuenta de la versatilidad que tiene esta música en cuanto a integrar elementos estilísticos de otros géneros.

La música carranguera se toca con un formato de cuatro instrumentos: guitarra marcante, tiple, requinto, guacharaca y voz; la diferencia con la rumba y el merengue campesinos radica en que se hace con tres guitarras (marcante, acompañante y puntera), la guacharaca y la voz también están presentes, y la guitarra acompañante puede ser reemplazada por el tiple. De acuerdo con lo observado en el trabajo de campo se puede afirmar que si acogemos la denominación de "músicas andinas centro-oriente", esta comprendería los siguientes aires: torbellino, guabina, rumba criolla, rumba campesina, merengue campesino y música carranguera. Todas estas expresiones aún se mantienen vivas, solo que en diferentes contextos.

\section{La música carranguera, al igual que la ruana, arropa el transcurrir de la vida campesina}

Desde el punto de vista estructural, la música carranguera no es complicada, sin embargo, en cuanto a su interpretación, se alcanzan niveles de ejecución virtuosística. Su aspecto formal ha sido trabajado por Moreno (2010), quien afirma que las piezas tienen el diseño estructural de la forma llamada canción, con una introducción, una sección estrófica y una sección de estribillo, las cuales se alternan hasta agotar el texto; en medio de dichas secciones se presentan unos interludios y termina con una sección de cierre. La sencillez de los elementos que constituyen esta música y sus niveles de redundancia facilitan su recordación; por su carácter alegre es propicia para acompañar los eventos en que el baile es uno de sus protagonistas. Aunque hoy en día la sección de la introducción puede ser de carácter libre y contrastar con las melodías de la estrofa, según Moreno, por lo general consiste en la "versión instrumental del tema de la canción o una variación de un motivo melódico de la estrofa o del coro". Con respecto a la extensión de cada una de las secciones, este mismo autor afirma que la introducción puede durar entre 24 y 32 compases, la estrofa 32, el estribillo entre 8 y 16 y los interludios 16 compases (p. 20). En lo que tiene que ver con las marchas armónicas, esta música no se diferencia de otras músicas populares en las que se usan acordes básicos de tónica, subdominante y dominante, sin embargo, se pueden encontrar giros modales ${ }^{7} y$, debido a que algunos de los músicos que conforman las agrupaciones carrangueras han transitado por el ámbito académico, la armonía se ha ido nutriendo con elaboraciones más sofisticadas. Moreno (2010) describe el movimiento armónico más usado de la siguiente manera: a) estrofa: I - V7 - I o I - IV - I- V7 - I; otra variante para la estrofa es: I - V - V7/IV - IV - I - V7 - I; b) en los estribillos, generalmente se hacen los mismos dos primeros movimientos mencionados para las estrofas o simplemente $\mathrm{V}$ - I (p. 15).

Los antecedentes de la música campesina pueden remontarse a la época de las "murgas" de los años cincuenta, que era una forma de llamar a los conjuntos musicales veredales, explica el músico Álvaro Suesca. Dice, además, que en esa época no se utilizaba el requinto para llevar la melodía sino que se tocaba la guitarra puntera chiquinquireña con el grave chiquinquireño que era una especie de tiple pequeño que tenía una joroba (fabricación de los constructores de instrumentos musicales Norato). En la siguiente copla, Suesca habla de cómo era la conformación de la murga:

\footnotetext{
7 Un ejemplo de esto es la canción de Jorge Velosa Vengo de Iguaque (mixolidio) que puede apreciarse en https://www. youtube.com/watch?v=ChNCITOH2zk.

8 En el libro de Moreno aparece 17, pero para mayor precisión
} se cifra de esta manera. 
Cirilo, Cleto, Cornelio, Beto, Pascasio y Cunsio son los del son, alegre murga de mi vereda, fue mi abuelito su fundador, al son del grave chiquinquireño, de la puntera y el guitarrón, chucho, dulzaina y la pandereta, y un buen copleroy un cantador.

La murga organizada por el abuelo del maestro Suesca se llamaba Los chiflamirlas. En ese entonces no había equipos tecnológicos de reproducción musical y eran las murgas las que amenizaban las fiestas. A propósito el maestro Suesca dice en una de las entrevistas para la presente investigación:

En esos tiempos ni que vitrolas, ni grabadoras, ni "picadiscos" (sic), era la murga la convidada por novios, suegros, también padrinos y se formaba que bailoteo y hay mi palabra pa'recordar que hasta cojitos y tullidiitos se levantaban para bailar, en todas las fiestas de San Isidro, San Agapito y San Agatón, Santa Cesilia, San Pedro y Pablo, Santa Rita y San Pascual Bailón. Si no había murga no había jolgorio, si no había murga no había función, iviva la murga Los chiflamirlas!, decía la gente con emoción.

En la mencionada copla de Suesca se alude a varias celebraciones religiosas, estas festividades fueron escenarios en los cuales se desarrollaron estas expresiones musicales, $y$ han servido, hasta nuestros días, como medios a través de los cuales los niños y jóvenes despiertan su interés por aprender a interpretarlas. Una de las más emblemáticas, la de San Pascual Bailón, es una tradición que se mantiene aún viva en diferentes veredas en las cercanías de Sogamoso. Marcos Pérez, un músico de la vereda de El Crucero, cuenta cómo su interés en la música nació de escuchar tocar a las agrupaciones en las fiestas de San Pascual Bailón y hace referencia a la existencia de una casta de músicos de "tradición san pascualera". Marcos afirma que estas celebraciones, en la actualidad, se hacen de manera esporádica debido a que su costo se ha incrementado a tal punto que las familias ya no tienen presupuesto para llevarlas a cabo. La paulatina desaparición de esta tradición afecta a la supervivencia de las agrupaciones veredales debido a que este es un espacio en el que ellas son protagonistas.

Lilia Montaña (1970) hace un bello relato literario de la manera como se celebraba el baile de San Pascual y, en un apéndice, incluye la transcripción de la música que se ejecutaba en ese entonces para este evento, dicha transcripción es del maestro Blas Emilio Atehortúa. Con respecto a estas transcripciones, en el libro no se aclara si esa era una música requerida para el rito o si solo se trata de un ejemplo en particular. En la actualidad, la música que se usa es variada pero el requisito es que sea instrumental, lo usual es que se ejecuten merengues y rumbas campesinas en el formato que usa guitarra puntera. Un grupo de músicos de Vélez (Santander) entrevistado dentro del proyecto, cuenta cómo se realiza en la actualidad este evento tradicional: según ellos, en la fiesta de San Pascual, el hecho de bailar es parte de la ofrenda, se baila como parte de la fe. Es una celebración en la que se usan atuendos especiales, dos niños se visten de ángeles (niño y niña), luego de rezar la novena de San Pascual y el rosario, los músicos comienzan a tocar música instrumental (no hay letras), siempre se baila sin dar la espalda a la estatua del santo, a la mitad de la pieza musical la niña vestida de ángel saca a bailar a otro parejo y luego el niño vestido de ángel saca a una pareja y así comienzan a participar todos del baile. Las parejas se alternan para bailar y tardan hasta la medianoche, en este momento se reza de nuevo la novena y el rosario, luego se tapa la estatua del santo y se descansa por una hora aproximadamente. A continuación, se reza otra novena y otro rosario y salen los ángeles a bailar de nuevo; este procedimiento de alternancia de baile vuelve a repetirse. Una de las poblaciones en las que aún se mantiene viva esta tradición es Morcá (Boyacá) y tal como sucedía en épocas pasadas, la fiesta puede prolongarse hasta por tres días.

En el relato de Montaña (1970) se describen algunas de las características de las agrupaciones musicales que participaban del baile de San Pascual y se resalta la importancia que ellas tenían en este evento:

En el patio alguien comenta:

-!Llegaron los músicos!

Y por la ancha puerta del corral aparecen cinco o seis campesinos de diferentes edades, con la cara recién rasurada y los ojos enrojecidos por las frecuentes noches de desvelo. Llevan el tiple, la guitarra o la bandola, arropados bajo la ruana como a un niño pequeño. También traen la maraca y la guacharaca, confeccionadas por ellos mismos; los primeros instrumentos han sido comprados con ocasión de su asistencia a las fiestas de Chiquinquirá. Un inquieto grupo de rapazuelos se apretuja en torno de aquellos improvisados artistas, que harán las delicias de los bailarines y a quienes se prodigan especiales atenciones (p. 400). 
Las agrupaciones veredales eran, y aún son (en los lugares donde prevalece la tradición), un elemento esencial en la mayoría de las celebraciones de carácter religioso. En el baile de San Pascual, los músicos tocan durante todo el evento y debido a la larga duración de este, a veces es necesario que se alternen diferentes agrupaciones. Según la descripción que hace Montaña (1970), la intervención de los músicos se inicia durante el rezo de los gozos en la novena para el Santo. Estos gozos hacen parte de la última sección de rezos que tienen como objetivo invitar a San Pascual a que haga presencia en la casa donde se está realizando el evento, la creencia consiste en que él llega, en forma espiritual, a abrir el baile. Montaña (1970) nos narra este episodio de la siguiente manera:

El anciano señor que ha ofrecido el baile, se inclina hasta el pequeño trocito del cirio que se ha colocado en la mitad del círculo hecho en el piso, con pétalos de flores, y, con el suyo, enciende el pequeño que está pegado al suelo. Se rezan los gozos de dos en dos, y entre cada interludio se toca una pieza de música. Como los gozos son diez estrofas en total, son cinco las intervenciones musicales, durante las cuales viene del cielo San Pascual, para "abrir el baile". Si el pequeño trocito de cirio que permanece encendido en medio de las flores deshojadas, mueve, impulsado por el viento, su pequeña lumbre, es señal segura de que el santo ha recibido aquella ofrenda $y$, agradecido, viene a acompañar a todos aquellos fieles devotos suyos y a bailar en medio de todos ellos, para que después, todos lo imiten (p. 407).

Según varios músicos de la región, en la actualidad la música que se prefiere para los bailes de San Pascual es del género merengue campesino. Montaña (1970) hace referencia a que se interpretaba una "música antigua" que ha sido compuesta por los mismos campesinos $y$ que según la autora, a algunas de esas piezas ellos las llamaban Media manta, Manta entera, Madrugada. También se interpretaban otros géneros de la música tradicional colombiana. Con respecto lo escrito por Montaña, se puede inferir que los músicos veredales hacían una apropiación particular, expresada en sus versiones singulares de lo que ella llama "música moderna". A propósito afirma que "se prefieren joropos, guabinas, torbellinos, pasillos y bambucos, que ejecutan a su manera, con algunos cambios caprichosos" (p. 411).

Las transcripciones musicales de Atehortúa que se incluyen en el libro de Montaña (1970) son trece piezas que vienen denominadas con el nombre de "bailes", de la siguiente manera: Primer baile, Segundo baile, y así sucesivamente hasta el quinto; luego vienen los bailes de los angelitos: Primer baile de los angelitos, Segundo baile de los angelitos, estos también son cinco; luego vienen el Baile de la niña y el dueño de la casa, el Baile de los ancianos (los dueños de casa), y termina con el Baile final. En el documento no hay información sobre si estas piezas corresponden a la música compuesta por los campesinos mencionada por la escritora, de todas maneras, se trata de una música que contiene las características de torbellinos, bambucos y guabinas. Sin embargo, no se puede afirmar lo anterior de manera contundente, ya que la escritura musical es apenas una guía y, en este caso, no da cuenta de su interpretación. El orden de ejecución de esta música corresponde al protocolo que se sigue en la secuencia de los bailes propios del rito. Las danzas que se interpretaban tenían un carácter zoomorfo, imitaban movimientos y describían situaciones relacionadas con animales; debido a esto recibían nombres como El baile de la perdiz, El baile del conejo, La gallina y el zorro, El gato y el ratón, La palomita y el gavilán, El pollito y la comadreja (Montaña, 1970, pp. 424-426).

El baile de San Pascual ha sido un escenario en el que los músicos campesinos han logrado desarrollar un estilo de música característico que es producto de la conservación de cierto repertorio original, de la incorporación de la música tradicional colombiana y de la apropiación de otros géneros populares, todo esto transmitido a diferentes generaciones mediante la oralidad. Los músicos campesinos adoptan con facilidad músicas que suenan en sus ambientes, que viajan de un lugar a otro sin respetar fronteras, responden rápidamente a lo cambiante de los gustos y apreciaciones, tanto propias como las de sus públicos. Estas actividades religiosas no se someten estrictamente a los cánones de la Iglesia católica, de hecho, no es común que se baile durante la celebración de una misa, y tampoco lo es, que se interprete música campesina dentro de la iglesia; sin embargo, el pueblo campesino la ha convertido en parte de sus ritos espirituales, y es así como aparece en las celebraciones de Navidad, durante los aguinaldos o en el evento Ilamado Misa Carranguera que se realiza en nombre de San José Obrero el $1^{\circ}$ de mayo en diferentes parroquias de Cundinamarca en la que se incorporan tonadas e instrumentos típicos del género carranguero dentro de esta liturgia. Según los músicos campesinos, la relación entre música y religión es un factor que ha contribuido al desarrollo de la música campesina en el centro-oriente de Colombia. Además del caso del baile 
de San Pascual, también es imprescindible mencionar el de las romerías. Según Ocampo (1977),

la romería es la expresión colectiva de las manifestaciones religiosas; en ellas, los "romeros" o "peregrinos" hacen la peregrinación al santuario, después de hacer el voto o promesa, que se presenta como garantía de los fieles para con Dios, si se obtiene el feliz suceso en alguna "gracia" que se pide.

Juan Pulido, habitante de Nuevo Colón (Boyacá) e integrante de la agrupación musical Pulido Son, se refiere a estas peregrinaciones y explica cómo viajaban las personas a pagar promesas por favores recibidos por algún santo. En estos viajes, afirma Juan, que se iban en los carros tocando utensilios que llevaban consigo, cantaban coplas percutiendo el tarro de la chicha, o la parte posterior de una linterna que era de material metálico y con una superficie conformada por ranuras, lo cual permitía que se usara como una guacharaca. Otros campesinos coinciden en sus historias con respecto a la presencia de la música en las romerías. En este sentido, cuentan que cuando no había carreteras y las peregrinaciones tenían que hacerse a pie, se tocaba música con instrumentos de cuerda y con instrumentos de percusión, estos últimos fabricados de materiales naturales de la región, como cucharas, carracas y chimborrios. Jorge Velosa (1983) narra con nostalgia

en las grandes romerías a Chiquinquirá, Chinavita, La Candelaria y otros lugares, el canto, la música y los bailes populares, siempre estuvieron presentes. Tal vez por eso y por ser cabecera de provincia, allí se establecieron algunos artesanos, maestros en la fabricación de instrumentos de cuerda, especialmente tiples y requintos que, según dicen las buenas lenguas, eran los más utilizados (citado en Serrano, 2011, p.136).

En su novela narrativa Siervo sin tierra, Eduardo Caballero Calderón se refiere también al uso de la música en estas peregrinaciones:

Más de quinientos promeseros de la Hoya del Chicamocha salieron aquella madrugada de la plazoleta de la Hacienda [...] vestidos con la ropita de las grandes ocasiones, con talegos de avío en la mano y una ruana al hombro para envolverse si se presentaba el caso de dormir en alguna parte [...] los hombres llevaban el tiple o el requinto en bandolera, y las mujeres, con dos o tres corroscas o jipas en la cabeza, arrastraban a sus niños de la mano [...] (citado por Serrano, 2011, p. 86).

En cuanto a la importancia que han tenido las romerías en el desarrollo de la música campesina, Nicole Ocampo (2014) afirma:

en medio de estas romerías por el territorio es que las músicas campesinas empiezan a consolidarse como una tradición que le canta a su tierra, a su entorno y a su tiempo. Campesinos y campesinas con sus tiples y guitarras entonaban sus tónicas y sus coplas, bailaban, comían y bebían chicha a lo largo de su peregrinaje de tal manera que guabinas y torbellinos, tonadas de los promeseros, se fueron consolidando como los géneros musicales por excelencia de esta región (p. 27).

En los últimos años, las reuniones familiares, las romerías, las fiestas de San Pascual y San Isidro y otras formas de circulación de la música campesina se han ido complementando o sustituyendo por espacios más públicos, más masivos como los concursos y festivales. También, los medios de comunicación, principalmente la radio, aunque en la actualidad con menos presencia que en los años ochenta, cuando apareció el éxito de Jorge Velosa, han contribuido a ampliar su difusión. La formación musical, que como se mencionó era espontánea en las veredas, hoy en día se hace en academias de las ciudades intermedias y pueblos, que los músicos experimentados crean para promocionar esta música y mantenerla viva, así como un medio de su propio sustento, incluso incursionando en niveles de formación universitaria, como es el caso de la Universidad de Cundinamarca. Esta música ha logrado conectar diversos escenarios de la vida de la región: la academia, entidades gubernamentales, organizaciones campesinas, medios de comunicación y la Iglesia. Desde estos estamentos varias personas se empeñan en promocionar e impulsar esta música representativa.

Campesinos y gestores culturales de la región sienten que hay una especie de invasión de otras músicas que resultan foráneas y esta es la razón por la que han emprendido la aplicación de diversas estrategias que les permitan fortalecer la preservación de su legado cultural, una de ellas son las prácticas pedagógicas de diferente naturaleza, otra es gestionar y organizar encuentros, convites y festivales con el afán de que las nuevas generaciones sigan interesándose en la música campesina. 
En la música carranguera actual se puede identificar que los estilos vienen determinados por los medios en los cuales circulan y se expresan. Existe música para diferentes espacios de divulgación: la música íntima que circula en el ámbito familiar; la música de concurso; la música de festival y la música comercial. La música íntima sigue llenando los espacios familiares y está destinada al esparcimiento y al baile, no tiene requerimientos especiales por lo que recurre a elementos rítmicos y melódicos básicos y no necesita cumplir con ningún formato instrumental particular. La música de concurso requiere de lo virtuosístico que es un elemento necesario para impresionar al jurado, esto hace que los bajos de la guitarra marcante y los solos del requinto tengan una elaboración melódica más florida. Por otro lado, en algunos concursos se exigen ciertos niveles de autenticidad tendientes a la conservación de los estilos típicos de interpretación, por lo que no se permiten alteraciones en el formato instrumental.

En cuanto a la música de festival, esta tiene más libertad en lo que tiene que ver con el despliegue de la creatividad debido a que está destinada a entretener a una audiencia, por esta razón no existen los mencionados requisitos de autenticidad y de conservación que son indispensables en los concursos. La música comercial, por supuesto, responde a las dinámicas de mercado y en ella se experimenta con el ánimo de atraer público y de tener éxito con propuestas novedosas, es así como apropia elementos de otras músicas que han sido apreciados por los consumidores, como la incorporación de instrumentación electrónica. Un grupo que ha tenido éxito en el ámbito de la música comercial con una propuesta de fusión es San Miguelito de la ciudad de Tunja, que en sus producciones introduce instrumentos característicos de la música rock como la guitarra eléctrica, la batería, el bajo eléctrico y los sintetizadores.

Así como en sus comienzos, la música campesina de centro-oriente sigue siendo versátil y es muy difícil que se mantenga estática. Son muy loables los intentos de conservarla como patrimonio, de coleccionarla como un objeto de museo, pero atajar sus dinámicas resulta complicado. Esto es una contradicción, ya que es imposible retenerla. La música es sonido y ritmo que no se deja atrapar ni guardar. Como en los años cincuenta y sesenta cuando las murgas entremezclaban diferentes géneros en sus interpretaciones, en la actualidad surgen propuestas que contienen elementos de otras músicas como la tropical, el rock y el jazz. La facilidad que tiene esta música de asimilar diferentes géneros y estilos musicales hace que sea un medio de encuentro intercultural, permite que traspase su territorio geográfico y se desplace por diferentes latitudes y cuerpos. Esta música se toca para ser bailada, "cuando no bailan los pies, bailan los corazones", afirma el maestro Jorge Velosa, y es a través del baile que transita por los cuerpos, invade territorios, "es un agenciamieno [sic] territorial en los cuerpos" (Maldonado, 2007).

Mediante la incorporación de diversos estilos y géneros, la música campesina logra abarcar más espacio y hace presencia en un número mayor de actividades individuales y colectivas, conformando lo que Ramírez (2006) Ilama una "sociedad musical". Es así como habita espacios familiares, religiosos, culturales y académicos, y transita además por los cuerpos de personas de diferentes edades, demarcando lo que en palabras de Maldonado (2007) sería su ritmo territorial. En estas prácticas y actividades en las que esta música hace presencia se generan discursos que contribuyen a fortalecer identidades, se construyen significados simbólicos que son propios de los grupos sociales que habitan el país carranguero, tal como lo afirma Ramírez:

la mediación de estas prácticas y su significado transita por un código, descifrable en su sentido preciso solo por la colectividad. Las prácticas, por lo tanto, son expresiones de argumentos visuales que se dirigen a la reconstrucción constante de la propia identidad (Maldonado, 2007, p. 250).

\section{El campesino del centro-oriente de Colombia siempre viaja con su ruana y su música}

La expansión de la música carranguera continúa por el mundo y ha sido apropiada por personas de otras culturas, no solo a partir de su escucha o consumo, sino también mediante su interpretación. Un ejemplo de esto último es el caso del grupo Sol Nacer del pueblo guambiano, o del grupo Los Chimborrios ${ }^{9}$ que tiene miembros de la cultura de los otavalos del Ecuador, otro ejemplo es el grupo llanero Arauko, que incluye en su formato instrumental el $\operatorname{arpa}^{10}$. ¿Cuáles son las razones para que ellos adopten esta música como suya? ¿Es posible que haya una posición política, de solidaridad con la comunidad campesina? ¿O se trata de la bús-

\footnotetext{
9 Su música se puede escuchar en este vínculo, https://www. youtube.com/watch?v=ROPRASS7IBw.

10Su música se puede escuchar en este vínculo, https://Www. youtube.com/watch?v=vUw4FhX36sY.
} 
queda de llenar una posibilidad de mercado o por simple gusto, o de la combinación de estos tres aspectos?

Aunque en el imaginario público esta música se asocie con determinada región, lo cierto es que su influencia atraviesa una diversidad de culturas y territorios, y es una música viva. Sin embargo, esta masificación y la presencia de los medios electrónicos de reproducción han afectado la actividad de los grupos veredales, que ven reducidas sus opciones de actuación debido a la disminución de las celebraciones religiosas, y porque muchas personas prefieren hacer sus fiestas con un equipo de sonido antes que requerir de sus servicios. Algunos de estos músicos campesinos buscan realizar sus proyectos musicales con un ánimo comercial y se proponen grabar la música que producen, sin embargo, no encuentran eco en los medios radiales, que son la primera fuente de divulgación a la que tienen acceso. No obstante, hay grupos, sobre todo los que son más reconocidos, que ya se han lanzado a explorar la posibilidad de promocionar su música a través de la plataforma Youtube.

Interrogarnos por el origen de esta música campesina ha permitido hacer un viaje por los caminos que ella transita y conocer los cuerpos en los que habita; se encuentran bellos lugares y amables personas en las que el espíritu de la música campesina aún vibra. Al viajar por la región del centro-oriente de Colombia se percibe la importancia que la música campesina tiene como fuerza viva que todavía persiste, lucha, insiste y resiste, en medio de otras expresiones musicales más fuertes. Aún subsisten grupos veredales, si se pregunta a algún vecino si hay músicos en las cercanías, siempre responden con varias opciones: el de la casa que queda localizada en tal lugar es músico, allá en la otra casa se reúnen a ensayar. La presencia de la carranga no se limita únicamente al espacio de la vereda, esta es una música que expande territorios, se toca de manera indiscriminada tanto en Boyacá como en Santander, Cundinamarca, los Llanos Orientales y trasciende la frontera llegando hasta Venezuela y Ecuador, la ruana carranguera arropa así un amplio territorio. La simpleza de sus contenidos gramático-musicales no es un límite, no es una barrera para lograr el efecto que produce en las personas que la viven y la bailan. Finalmente, tratar de determinar lo que esta música es en su esencia no es tan importante como indagar sobre lo que ella hace: movilizar a todo un pueblo, al pueblo carranguero en torno a ella. Se trata de un conglomerado de personas con diversos intereses: gente que la crea, gente que simplemente quiere bailarla, gente que está interesada en promoverla en diferentes espacios culturales, gente que busca enseñarla y aprenderla, gente que realiza diferentes actividades comerciales con ella y gente que quiere investigarla.

\section{Referencias}

Amaya, C. (21 de julio del 2013). Congreso de la República de Colombia. Recuperado el 20 de agosto del 2015 de http://www.camara. gov.co/.../5619-pl005-2013c-la-ruana-simbolo-nacional.

Cook, N. (2001). De Madonna al canto greogoriano. Madrid: Alianza.

González, J. (2012). La construcción de una identidad colombiana a través del bambuco en el siglo XIX. Pamplona: Universidad de Pamplona.

Maldonado, J. (2007). El territorio musical de la humanidad.Thémata39,459-464. Recuperadode https://www.researchgate.net/publication /47628249_El_territorio_musical_de_la_humanidad.

Montaña, L. (1970). Mitos, leyendas, tradiciones y folklore de Lago de Tota. Tunja: La Rana y El Águila.

Ocampo, J. (10 de enero de 1977). Biblioteca virtual Luis Ángel Arango. Recuperado el 20 de agosto del 2015 de El pueblo boyacense y su folclor. http://www.banrepcultural.org/ blaavirtual/folclor/pueboy/pueboy7a.htm.

Ocampo, N. (2014). Las músicas carrangueras en la conformación de un territorio. Bogotá: Pontificia Universidad Javeriana.

Ramírez, J. (2006). Música y sociedad: la preferencia musical como base de la identidad social. Sociológica (60), 243-270. México D. F.: Universidad Autónoma Metropolitana.

Serrano, C. (2011). Imaginando con musiquita un país. Bogotá: Fica.

Squicciarino, N. (1986). El vestido habla. Madrid: Cátedra.

Vanegas, T. (7 de marzo del 2015). Ruana y carranga. (L. Zambrano, entrevistador).

Vila, P. (2002). Música e identidad. La capacidad interpeladora y narrativa de los sonidos. Cuadernos de Nación, tomo: Músicas en transición. Bogotá: Ministerio de Cultura.

Velosa, J. (1983). La cucharita y no sé qué más: historias para cantar. Bogotá: Carlos Valencia. 


\section{Contenido}

VOL. VII N.o 7 - Enero 2018

4 resemancen

\section{Música y Cultura}

Ruana y carranga: dos símbolos campesinos de origen múltiple Leonardo Zambrano Rodríguez

\section{Música y pensamiento}

18 Arte y música como apropiación social del conocimiento en el proyecto regional Aprociencia Humberto Galindo Palma

36

La evaluación formativa desde la concepción de Phillipe Perrenoud: una experiencia en la clase de Historia de la Música Boris Alfonso Salinas Arias

\section{Música en clave}

48

Creación de herramientas de análisis para

el estudio del contrapunto tonal: una aproximación desde la música popular María Cristina Vivas Barrera, Adrián Camilo Ramírez Méndez, Juan Gabriel Alarcón (colaborador)

(1) Tiple solista en Colombia:

Sergio Andrés Camero Tierradentro, Jorge Iván Ramírez Marín, Yordi Andrey Vargas Guzmán

\section{Separata}

Niebla de Chipre para orquesta de cuerdas segundo premio en el Concurso Internacional de Composición "Música Jove",

Valencia-España 2016

Andrés A. Garzón Charry

Convocatoria Revista No. 8

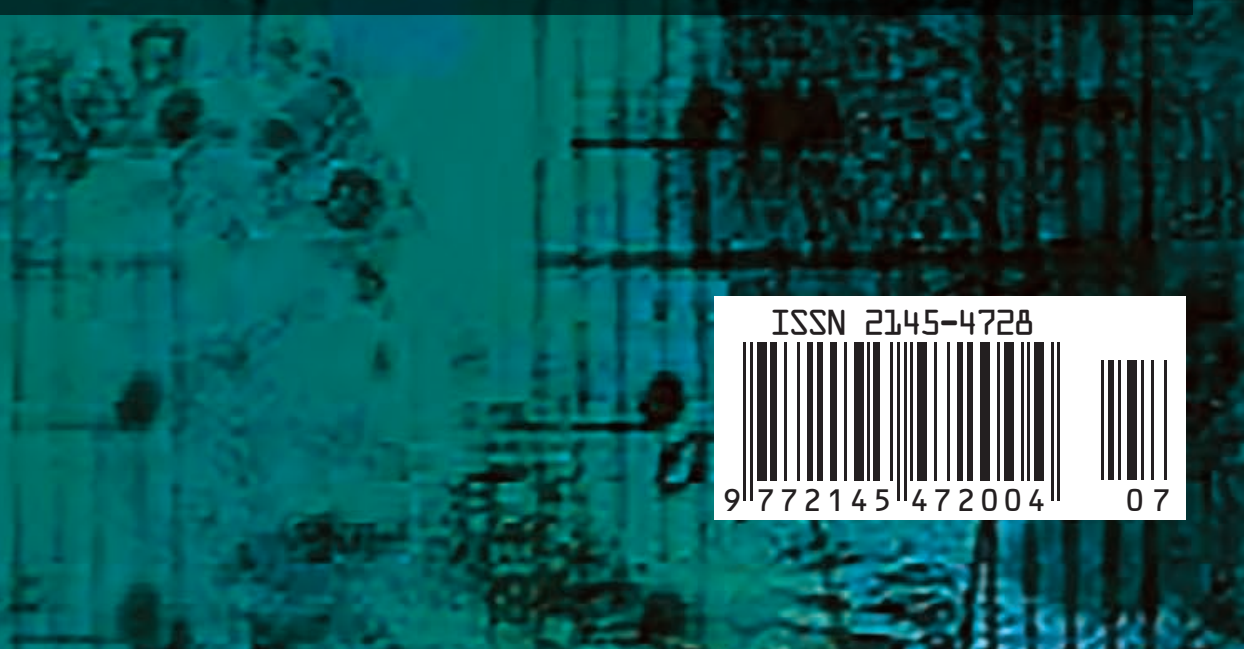

